\title{
Intramedullary cavernoma presenting with hematomyelia: report of two girls
}

\author{
Erwin M. J. Cornips • Pauline A. C. P. Vinken • \\ Mariel Ter Laak-Poort • Emile A. M. Beuls • \\ Jacobine Weber • Johannes S. H. Vles
}

Received: 15 September 2009 / Published online: 29 October 2009

(C) The Author(s) 2009. This article is published with open access at Springerlink.com

\begin{abstract}
Introduction Less than 20 children with intramedullary cavernoma ( $\mathrm{ImC}$ ) have been reported in the English literature; however, cases with an unfavorable outcome may be underreported. Whereas these are predominantly boys, we report two girls who presented with hematomyelia (one cervical, one thoracic) and an acute, severe neurological deficit.

Case material A 10-year-old girl complaining about lower thoracic pain for several days suddenly developed lower body dysesthesias and paraparesis. Magnetic resonance (MR) demonstrated hematomyelia (T8-T11), intramedullary edema (T6-L1), and an $\mathrm{ImC}$ at $\mathrm{T} 9-\mathrm{T} 10$. Within an hour, she progressed to paraplegia and was therefore operated immediately. She slowly recovered regaining independent ambulation and continence. MR after 2 years shows no recurrence. A 7-year-old girl suddenly developed cervicalgia and paresis of her left arm and leg. MR demonstrated hematomyelia and an ImC at C4-C6. She gradually recovered with minimal residual deficit at 3 months and was subsequently operated uneventfully. Multiple cerebral cavernomas and a familial autosomal cavernous malformation syndrome were diagnosed. The
\end{abstract}

E. M. J. Cornips $(\bowtie) \cdot$ P. A. C. P. Vinken · M. Ter Laak-Poort

E. A. M. Beuls

Department of Neurosurgery,

Maastricht University Medical Center,

P. Debyelaan 25, P.O. Box 5800, 6202 AZ Maastricht,

The Netherlands

e-mail: e.cornips@mumc.nl

J. Weber · J. S. H. Vles

Department of Child Neurology,

Maastricht University Medical Center,

Maastricht, The Netherlands following 1.5 years, she complained of intermittent cervicalgia and left brachial dysesthesias, with MR suggesting active residual cavernoma. Interestingly, her complaints gradually disappeared, and she is currently asymptomatic. MR after 3.5 years shows minimal cord swelling no longer suggesting active residual cavernoma. Conclusion With adequate surgical treatment either in the acute phase in case of dramatic deterioration or after clinical recuperation, prognosis of symptomatic $\mathrm{ImC}$ may be surprisingly good. However, subtotally resected lesions and/or syndromal cases may recur, requiring further treatment. Definitive answers await more cases with longer follow-up.

Keywords Cavernoma $\cdot$ Genetics $\cdot$ Hematomyelia Intramedullary cavernous angioma $\cdot$ Pediatric neurosurgery

\section{Introduction}

Intramedullary cavernomas $(\mathrm{ImC})$ are rare lesions especially in children, in whom they represent $1 \%$ of all intramedullary lesions [23]. As such, less than 20 symptomatic cases have been reported in the English literature [1, 2, 6, 9, 10, 16, 18-20, 23-25] and predominantly in boys (Table 1). These invariably presented with an acute, severe neurological deficit followed by rapid deterioration due to hematomyelia [23]. Confronted with such a dramatically affected patient, the attending neurosurgeon, due to the rarity of the condition, finds no guidelines in the literature and has to decide if and when to operate on a case-by-case basis, based on the child's clinical presentation, magnetic resonance (MR) findings, and his or her personal preference.

We report two girls presenting with hematomyelia (one cervical, one thoracic) and an acute, severe neurological deficit. We present their clinical and radiological details as 
Table 1 Clinical characteristics of children with intramedullary cavernoma in the literature

\begin{tabular}{|c|c|c|c|c|}
\hline Authors & Gender & Age (years) & ImC anatomical level & ImC multiple levels \\
\hline Odom et al. [20] & $\mathrm{F}$ & 13 & $\mathrm{C} 3-\mathrm{C} 4$ & No \\
\hline McCormick et al. [16] & M & 15 & T8-T9 & No \\
\hline \multirow[t]{2}{*}{ Anson and Spetzler [1] } & $\mathrm{F}$ & 14 & $\mathrm{C} 2$ & Cerebral cavernomas and familial history \\
\hline & M & 17 & $\mathrm{C} 3-\mathrm{C} 7$ & No \\
\hline Furuya et al. [9] & $\mathrm{F}$ & 14 & $\mathrm{~T} 10-\mathrm{T} 11$ & Unknown \\
\hline \multirow[t]{2}{*}{ Tu et al. [25] } & M & 7 & $\mathrm{C} 3-\mathrm{C} 4$ & Unknown \\
\hline & M & 18 & C7-T1 & Unknown \\
\hline Scott et al. [24] & M & 13 & Cervical spinal cord & Unknown \\
\hline \multirow[t]{2}{*}{ Deutsch et al. [6] } & M & 13 & $\mathrm{~T} 3$ & 4 intracranial cavernomas \\
\hline & M & 8 & $\mathrm{C} 2$ & 6 intracranial cavernomas \\
\hline \multirow[t]{2}{*}{ Nagib and O'Fallon [18] } & M & 10 & $\mathrm{~T} 4$ & Unknown \\
\hline & $\mathrm{F}$ & 16 & $\mathrm{~T} 4$ & Unknown \\
\hline Bakir et al. [2] & M & 14 & $\mathrm{C} 6-\mathrm{C} 7$ & Unknown \\
\hline \multirow[t]{4}{*}{ Jallo et al. [10] } & M & 13 & $\mathrm{~T} 4$ & 7 \\
\hline & M & 8 & $\mathrm{C} 1$ & 6 \\
\hline & M & 18 & $\mathrm{C} 7-\mathrm{T} 1$ & No \\
\hline & M & 18 & $\mathrm{~T} 1-\mathrm{T} 2$ & No \\
\hline Santoro et al. [23] & M & 11 & $\mathrm{C} 1$ & 4 cerebral and 1 pontine cavernoma \\
\hline Noudel et al. [19] & $\mathrm{F}$ & 12 & $\mathrm{~T} 11$ & No \\
\hline \multirow[t]{2}{*}{ Present study } & $\mathrm{F}$ & 7 & $\mathrm{C} 5$ & No \\
\hline & $\mathrm{F}$ & 10 & T9-T10 & No \\
\hline
\end{tabular}

$C$ cervical, $F$ female, $\operatorname{Im} C$ intramedullary cavernoma, $M$ male, $T$ thoracic

well as our surgical strategy and outcome. Finally, as one of the girls turned out to have a familial autosomal cavernous malformation syndrome, we review the pertinent literature as well.

\section{Case material}

Case 1

\section{History and examination}

A 10-year-old girl complaining about dorsalgia for several days suddenly developed lower body dysesthesias and a paraparesis. An L1 sensory-motor level, lower limb hyperreflexia including Babinski's signs, and decreased rectal sphincter tone were noted. Emergency MR demonstrated hematomyelia (T8-T11), intramedullary edema (T6-L1), and an ImC at T9-T10 (Fig. 1a). Within $2 \mathrm{~h}$ after admission, paraparesis progressed to paraplegia, and therefore, the girl was operated immediately.

\section{Operation}

We had no time to localize the lesion preoperatively. Consequently, we removed three thoracic laminae and two more after durotomy revealing insufficient exposure of the lesion, which appeared as a dark blue clot shining through the pia mater. After midline myelotomy, the hematoma presented itself, and the cavernoma was gently mobilized and resected.

\section{Postoperative course}

The girl slowly recovered, regaining minimal voluntary movement after 10 days, continence after 9 months, and independent ambulation after 12 months. Early postoperative MR confirmed complete resection of an apparently solitary cavernoma (Fig. 1b), whereas 2 years postoperative MR shows a thin spinal cord without evidence of local recurrence (Fig. 1c) and a kyphoscoliosis which we are closely following (Fig. 1d).

Case 2

\section{History and examination}

One day after a fall during skating, a 7-year-old girl suddenly developed cervicalgia and severe paresis of her left arm and leg (grades 1-2 out of 5 according to the American Spinal Injury Association). MR demonstrated hematomyelia at $\mathrm{C} 4-\mathrm{C} 6$ and an $\mathrm{ImC}$ at $\mathrm{C} 5$ (Fig. 2a). Within 

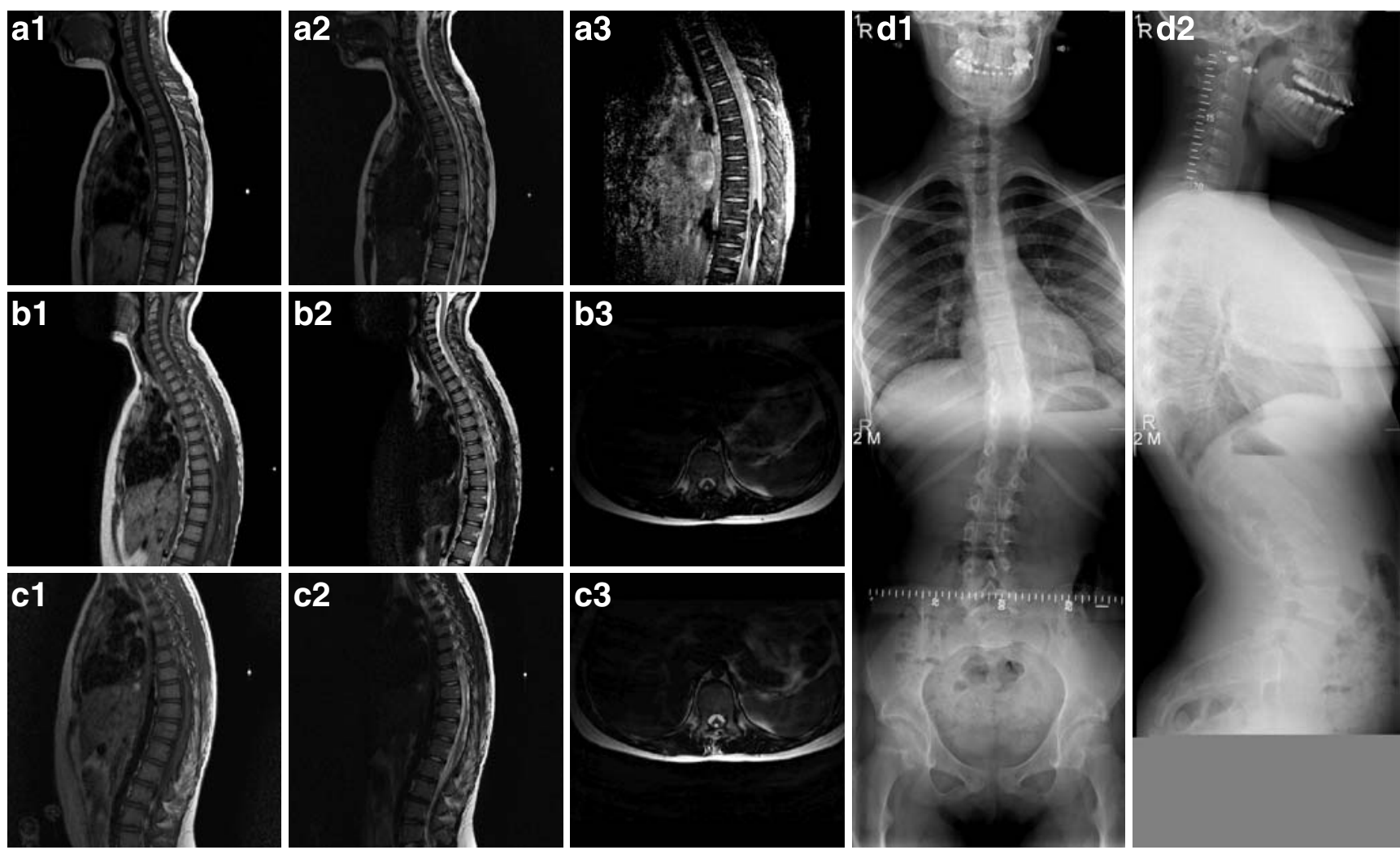

Fig. 1 a1-a3 Preoperative sagittal T1, T2, and T2 FFE (fast field echo) MR images revealing a markedly swollen cord, including intramedullary edema (T6-L1), hematomyelia (T8-T11), and an ImC at T9-T10; b1-b3 3 months postoperative sagittal T1, T2, and axial T2 MR images confirming complete resection; $c 1-c 32$ years

the next 10 days, her paresis improved to a grade 4, and at 3 months, her residual deficit was minimal.

\section{Operation}

At that time, she was operated using a C3-C7 laminoplastic technique and motor evoked potential monitoring. The cord at C4-C5 was clearly swollen, and the exact position of the cavernoma was determined using ultrasonography (Fig. 3b). Subtle subpial yellow-blue discoloration was apparent after sectioning the left $\mathrm{C} 4-\mathrm{C} 5$ denticulate ligament and gently rotating the spinal cord to the right (Fig. 3a). After lateral myelotomy, the hematoma presented itself; however, mobilizing and resecting the cavernoma was difficult due to a rather limited lateromedial view inside the spinal cord.

\section{Postoperative course}

The girl did well after the operation showing no new neurological deficits. Multiple small cerebral cavernomas and a familial autosomal cavernous malformation syndrome were diagnosed with mutation of the MGC4607/ postoperative sagittal T1, T2, and axial T2 MR images demonstrating a thin spinal cord without evidence of local recurrence; $d 1, d 22$ years postoperative anteroposterior and lateral spinal X-rays to monitor kyphoscoliosis

malcavernin/CCM2-gen (Fig. 2b). The following 1.5 years, she complained of intermittent cervicalgia and left brachial dysesthesias, with MR suggesting active residual cavernoma (Fig. 2c). Interestingly, her complaints gradually disappeared, and she is currently asymptomatic. MR after 3.5 years shows minimal cord swelling no longer suggesting active residual cavernoma (Fig. 2d).

\section{Discussion}

Incidence, clinical presentation, and bleeding risk

ImC are rare lesions in adults but even more in children, representing $5 \%$ and $1 \%$, respectively, of all intramedullary lesions at tertiary referral centers $[5,23]$. As such, less than 20 symptomatic children have been reported in the English literature $[1,2,6,9,10,16,18-20,23-25]$ (Table 1), invariably presenting with an acute, severe neurological deficit followed by rapid deterioration due to hematomyelia [23]. Adults, on the other hand, present with slowly progressive deficits or an acute deficit followed by a slow, stepwise deterioration with episodes of some clinical 

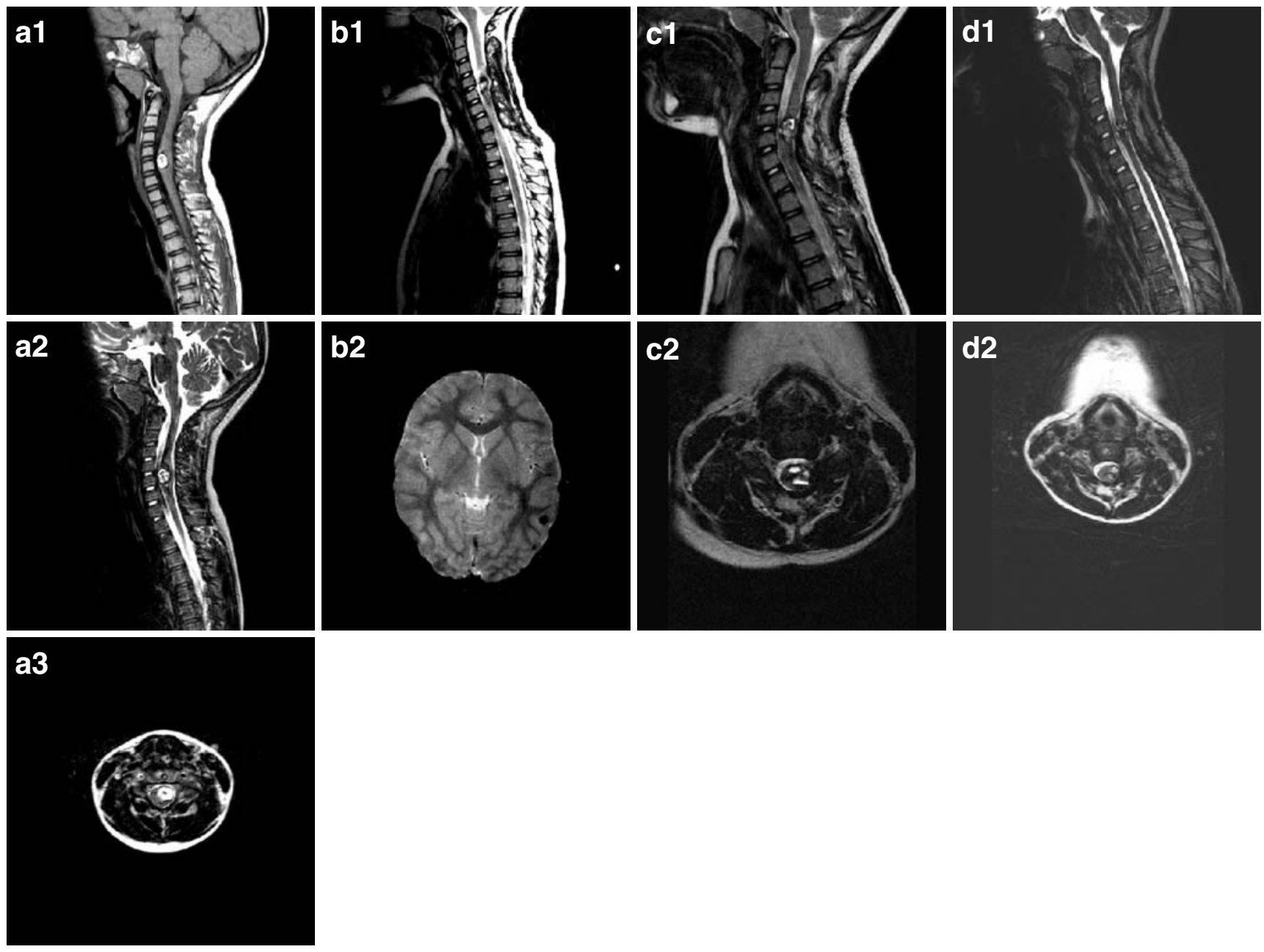

Fig. 2 a1-a3 Preoperative sagittal T1, T2, and axial T2 MR images revealing a markedly swollen cord, including hematomyelia at $\mathrm{C} 4-\mathrm{C} 6$ and a left anterolateral $\mathrm{ImC}$ at $\mathrm{C} 5 ; b 1, b 23$ months postoperative sagittal T2 and axial T2 FFE (fast field echo) MR images, note

improvement, caused by repeated microhemorrhage followed by gliosis or iterative thrombosis within the cavernoma $[8,15,19]$. Our first patient complained about dorsalgia for several days and then suddenly developed lower body dysesthesias and a paraparesis, which within $2 \mathrm{~h}$ after admission progressed to paraplegia. Our second patient suddenly developed cervicalgia and severe paresis of her left arm and leg 1 day after a fall. The acute presentation in both cases is in line with the literature; however, the second patient remained in stable clinical condition over the following days and therefore did not require emergency surgery.

The clinical presentation of $\mathrm{ImC}$ in general is quite variable, often including both sensory and motor symptoms, resulting in pain and paresis. As such, Zevgaridis et al. [29] distinguished three major patterns in the clinical course of 117 symptomatic $\operatorname{ImC}$ in patients between 12 and 88 years old. Group A (30\%) suffered multiple

multiple small cerebral cavernomas; $c 1, c 22.5$ years postoperative sagittal and axial T2 MR images, the cord still appears swollen; $d 1, d 2$ 3.5 years postoperative sagittal and axial T2 MR images, the cord now appears less swollen and the child is asymptomatic

episodes of discrete neurological deterioration and varying degrees of recovery in between. Group B (41\%) suffered slowly progressive neurological deterioration. Group $\mathrm{C}$ (26\%) suffered sudden onset of symptoms and rapid decline over hours or days $(\mathrm{C} 1,16 \%)$, which is common in children $[10,18]$, or a little slower over several weeks $(\mathrm{C} 2,10 \%)$. Clearly both cases presented in this report belong to group $\mathrm{C} 1$.

There is no literature specifically addressing the bleeding risk of ImC in pediatric patients. Most clinical series deal mainly or exclusively with adult patients and demonstrate a higher bleeding risk (regardless of age) for ImC as compared to their cerebral counterparts: the annual bleeding risk for cerebral cavernomas is believed to be about $0.7-1.3 \%$ [3, 13, 21], for brainstem cavernomas about 2.7\% [19], and for ImC about 1.6-4.5\% [18, 19, 22]. Moreover, the potential that hemorrhage may cause significant morbidity is higher for $\operatorname{ImC}$ than for their 


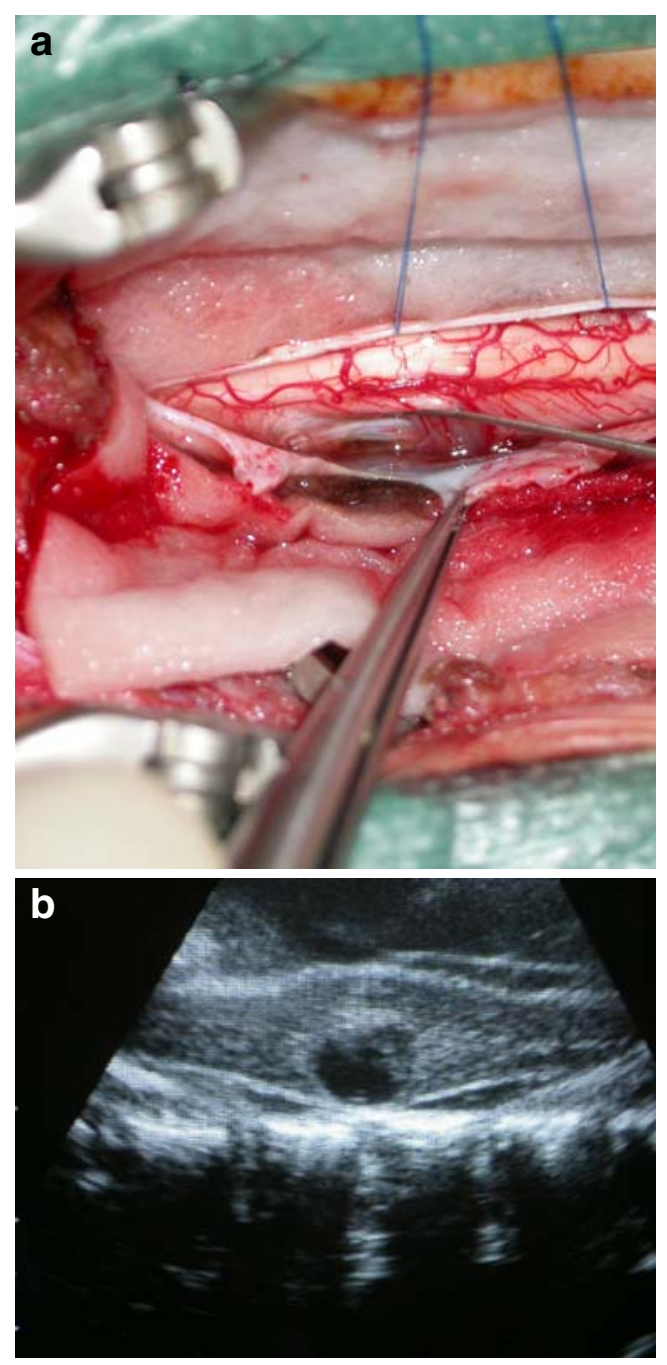

Fig. 3 a Macroscopic intraoperative image at C4-C5 (left dorsolateral view, one denticulate ligament sectioned) showing subtle subpial yellow-blue discoloration at the lateral surface of the spinal cord. b Ultrasonic intraoperative image at C3-C6 (sagittal view) specifying the exact location of the cavernoma in the swollen cord segment

cerebral counterparts because of the confined parenchymatous space in which ImC are located.

\section{Gender distribution and age at presentation}

Deutsch et al. [5] postulated that adult ImC are equally distributed among both sexes; however, a female predisposition in those presenting with hemorrhage (female/male ratio 2:1) [29] may be attributable to a hormonal effect increasing the risk of hemorrhage. More recently, Santoro et al. [23] performed an extensive literature review and calculated a female/male ratio of 1.1:1. In contrast, a male predisposition is reported in children (female/male ratio $1: 2$ ), and the mean age they present with hematomyelia is 9.1 years (range 7 months-17 years) according to Scott et al. [24] or 13.2 years (range 8-17 years) according to
Noudel et al. [19]. In this regard, some authors believe that hormonal factors may influence the clinical onset of cavernomas in puberty [19]. Our report adds two girls to the literature and challenges the reported male predisposition in children (Table 1).

Imaging characteristics, anatomical distribution, and genetic predisposition

MR is the golden standard to diagnose cavernomas in any location, as myelography and computed tomography are much less sensitive [1] and cavernomas are angiographically occult [12]. ImC typically have a mixed signal intensity on MR scans, including a hyperintense core lesion and a rim of low signal intensity caused by hemosiderin deposition around the cavernoma on T2weighted images [1]. Their size varies from $0.8-5.4 \mathrm{~cm}$ (mean 1.4-1.7 cm) [3, 5, 10, 15], and typically, they are small, round, or ovoid well-defined lesions $[5,10]$ situated dorsolaterally in the spinal cord [25] where they may reach the surface. The $\operatorname{ImC}$ in our patients were of intermediate size and situated dorsomedially (case 1) and left (dorso)laterally (case 2). The extent of hematomyelia (T8-T11) and intramedullary edema (T6-L1) in the former patient, however, made an exact delineation of the cavernoma difficult.

According to the literature, $\mathrm{ImC}$ in adults are more common in the thoracic cord, whereas $\mathrm{ImC}$ in children are equally distributed in the cervical and thoracic cord [18, 19] (Table 1). As such, our first patient had a cavernoma at T9-T10 and our second patient at C5. Importantly, ImC may occur in association with cerebral or systemic lesions $[1,10]$. Multiple lesions are typically seen in the so-called inherited cerebral cavernous malformation disorder [17], which was diagnosed in our second patient. To date, three loci have been identified for this disorder: CCM1 on chromosome arm $7 \mathrm{q}, \mathrm{CCM} 2$ on $7 \mathrm{p}$ (our second patient), and CCM3 on 3q, which may be responsible for approximately $40-50 \%, 10-20 \%$, and $40 \%$ of inherited cases, respectively [4, 7]. In fact, as many as $12-40 \%[5,10]$ of patients and especially children and young adults with ImC have other cavernomas in their central nervous system (Table 1). Complete neuraxis imaging in all patients and particularly in the younger age group is therefore mandatory [10, 27].

Few cases have been reported with multifocal (intramedullary and cerebral) cavernomas yet without a positive family history, and several theories have been proposed to explain their occurrence: a neoplast-like process with hormonal influence during pregnancy, the possible seeding of a lesion along a biopsy track, the intralesional presence of endothelial cell expressing proliferating cell nuclear antigen, the occurrence of cavernomas in areas previously 
irradiated, and an incomplete penetrance or even a misdiagnosis of the disease [17, 23, 28].

Surgical strategy and outcome

Some authors recommend resection for every patient with symptomatic ImC and even for those who have minimal symptoms $[10,24]$. They argue that once symptoms and signs caused by hemorrhage have appeared, the patient will likely experience future neurological decline, whereas after microsurgical resection by experienced hands, a stable or improved functional status is achieved in $92-94 \%$ of patients [10, 29] independent of age, gender, and lesion location [29]. On the other hand, Kharkar et al. [11] recently evaluated the natural history of conservatively managed symptomatic ImC and did not observe a significant, permanent neurological decline in a cohort of ten patients during a mean follow-up period of 80 months. Of note, all but one were adult patients who may have a different clinical course as previously outlined, and the study design was retrospective nonrandomized (conservatively managed patients presenting mainly with paresthesias, surgically managed patients presenting mainly with pain and paresis). The authors carefully conclude that they may have identified a distinct subgroup of patients with symptomatic ImC that may have a much lower risk of rehemorrhage.

Most neurosurgeons would agree that dissection must be confined to the thin layer of hemosiderin laden gliosis surrounding the $\mathrm{ImC}$ to limit damage to the normal adjacent spinal cord tissue. According to some authors [19], this would even obviate the use of neurophysiological monitoring which they consider time-consuming and of debated reliability. Others including us prefer neurophysiological monitoring for every elective intramedullary resective procedure $[6,10,14]$. Furthermore, intraoperative ultrasound typically shows a hypointense signal at the site of recent hemorrhage [10], helps to localize the lesion if not readily visible on the cord surface [25], and helps to determine the optimal entry point to approach the lesion.

There is considerably more debate regarding the optimal timing for resection, which is simply not known, and factors such as severity of the patients clinical condition, presence (or absence) of clinical progression, anatomical level of the lesion, and attending surgeons experience would be taken into account. Some authors propose 4 to 6 weeks after hemorrhage as an optimal time to operate, as during such time interval, a gliotic plane would have formed around the cavernoma, enabling the surgeon to safely separate cavernoma from surrounding cord tissue $[10,12,29]$. This is exactly what we did in case 2 , who remained in stable clinical condition initially and then gradually recovered until she was operated 3 months after hemorrhage. In case 1 who rapidly progressed to paraplegia, we did not hesitate to operate immediately, and fortunately, the girl demonstrated remarkable recovery regaining continence and independent ambulation over the following months. In fact, in such situation, there may be imminent spinal cord infarction due to a steep pressure rise in the spinal cord, which is lined by nonelastic pia mater. Therefore, rapid pressure relief may be the only way to prevent irreversible spinal cord infarction.

It is essential to achieve radical removal during the first operation because any ImC residue may lead to further hemorrhage [23], and a second operation may present greater surgical difficulties. Rebleeding risk may be as high as $17.6 \%$ according to Vishteh et al. [27] or even $66 \%$ according to Sandalcioglu et al. [22] and may cause recurrent myelopathy (9\%) [26]. Whereas our first patient clearly has no residual cavernoma on postoperative MR scans, our second patient seemed to have an actively leaking residual cavernoma on initial follow-up MR scans and complained of intermittent cervicalgia and left brachial dysesthesias for approximately 1.5 years postoperatively. Interestingly, her complaints gradually disappeared and she is currently asymptomatic. MR after 3.5 years shows minimal cord swelling no longer suggesting active residual cavernoma. Little if anything is found in the literature concerning the difficult dilemma between follow-up and reoperation in case of residual cavernoma, especially in the setting of multiple cavernomas in children who have a long life expectancy and are otherwise doing fine. It is generally believed subtotally resected lesions and/or syndromal cases tend to recur $[1,10,12,18,24,26]$. In this regard, Scott et al. [24] have suggested that central nervous system cavernomas may frequently bleed silently, producing lowpressure small-volume hemorrhages which are radiologically invisible. Such hemorrhages may not be of a critical volume or may not be in a critical location and therefore may not be life threatening; however, they may expand with time and irritate the spinal cord, which may become gliotic and edematous [10, 24]. On the other hand, one should keep in mind that especially early postoperative MR images may be misleading and therefore misinterpreted, as low-intensity signals of postoperative scar tissue may be misdiagnosed for residual cavernoma and that MR images may become more reliable at least 6 months postoperatively [19]. Clearly, definitive answers await more cases with longer follow-up, and until then, surgical decisions have to be made on a case-by-case basis.

Finally, therapeutic indications remain controversial for asymptomatic ImC in sporadic as well as nonsporadic cases [19]. Some recommend surgical resection for readily accessible $\operatorname{ImC}[5,6,22]$, whereas others recommend an expectant policy and regular clinicoradiological follow-up for deeper lesions $[1-3,10,12]$. 
Long-term follow-up

Vishteh et al. [26] reported delayed complications in four of 17 patients $(23.5 \%)$ with surgically treated ImC. These complications were mainly symptomatic rehemorrhage as a result of incomplete resection, or less frequently symptomatic spinal cord tethering. Clinical symptoms of spinal cord tethering include severe headaches, neck pain, arm or leg pain irresponsive to medical therapy, and/or progressive neurological deficit, which are all related to the level of spinal cord tethering. Surgical detethering is indicated in patients who develop new or progressive symptoms in the late postoperative period and are radiographically suspect for tethering. In children, spinal deformity is another potential complication after multilevel laminectomy [18]. As children may develop delayed spinal deformity and/or spinal cord tethering during longitudinal growth, regular radiological follow-up is indicated until they have reached adult stature (Fig. 1d). Whether such spinal deformity may be prevented by replacement laminoplasty techniques remains a matter of debate $[18,19]$.

\section{Conclusion}

Less than 20 children with $\operatorname{ImC}$ have been reported in the English literature; however, cases with an unfavorable outcome may be underreported. We report two girls presenting with an acute, severe neurological deficit due to hematomyelia, thereby challenging the male predominance in this age group. MR of the entire neuraxis is mandatory, as these children are more likely to harbor a familial autosomal cavernous malformation syndrome. With adequate surgical treatment either in the acute phase or after clinical recuperation, prognosis may be surprisingly good. Incompletely resected lesions and/or syndromal cases may recur, requiring further treatment. Definitive answers await more cases with longer follow-up especially after subtotal resection; however, as long as patients remain in stable condition, careful clinical and radiological follow-up may be an alternative to reoperation.

Open Access This article is distributed under the terms of the Creative Commons Attribution Noncommercial License which permits any noncommercial use, distribution, and reproduction in any medium, provided the original author(s) and source are credited.

\section{References}

1. Anson JA, Spetzler RF (1993) Surgical resection of intramedullary spinal cord cavernous malformations. J Neurosurg 78:446-451
2. Bakir A, Savas A, Yilmaz E, Savas B, Erden E, Caglar S, Sener O (2006) Spinal intradural-intramedullary cavernous malformation. Case report and literature review. Pediatr Neurosurg 42:35-37

3. Canavero S, Pagni CA, Duca S, Bradac GB (1994) Spinal intramedullary cavernous angiomas: a literature meta-analysis. Surg Neurol 41:381-388

4. Craig HD, Gunel M, Cepeda O, Johnson EW, Ptacek L, Steinberg GK, Ogilvy CS, Berg MJ, Crawford SC, Scott RM, Steichen-Gersdorf E, Sabroe R, Kennedy CT, Mettler G, Beis MJ, Fryer A, Awad IA, Lifton RP (1998) Multilocus linkage identifies two new loci for a Mendelian form of stroke, cerebral cavernous malformation, at $7 \mathrm{p} 15-13$ and $3 \mathrm{q} 25.2-27$. Hum Mol Genet 7:1851-1858

5. Deutsch H, Jallo GI, Faktorovich A, Epstein F (2000) Spinal intramedullary cavernoma: clinical presentation and surgical outcome. J Neurosurg 93:65-70

6. Deutsch H, Shrivistava R, Epstein F, Jallo GI (2001) Pediatric intramedullary spinal cavernous malformations. Spine 26:E427E431

7. Dubovsky J, Zabramski JM, Kurth J, Spetzler RF, Rich SS, Orr HT, Weber JL (1995) A gene responsible for cavernous malformations of the brain maps to chromosome 7q. Hum Mol Genet 4:453-458

8. Fazi S, Menei P, Mercier P, Dubas F, Guy G (1992) Cavernomas of the spinal cord: report of two patients. Br J Neurosurg 6:149 152

9. Furuya K, Sasaki T, Suzuki I, Kim P, Saito N, Kirino T (1996) Intramedullary angiographically occult vascular malformations of the spinal cord. Neurosurgery 39:1123-1130 discussion 11311122

10. Jallo GI, Freed D, Zareck M, Epstein F, Kothbauer KF (2006) Clinical presentation and optimal management for intramedullary cavernous malformations. Neurosurg Focus 21:e10

11. Kharkar S, Shuck J, Conway J, Rigamonti D (2007) The natural history of conservatively managed symptomatic intramedullary spinal cord cavernomas. Neurosurgery 60:865-872 discussion $865-872$

12. Kondziella D, Brodersen P, Laursen H, Hansen K (2006) Cavernous hemangioma of the spinal cord-conservative or operative management? Acta Neurol Scand 114:287-290

13. Kondziolka D, Lunsford LD, Kestle JR (1995) The natural history of cerebral cavernous malformations. J Neurosurg $83: 820-824$

14. Kothbauer K, Deletis V, Epstein FJ (1997) Intraoperative spinal cord monitoring for intramedullary surgery: an essential adjunct. Pediatr Neurosurg 26:247-254

15. Labauge P, Bouly S, Parker F, Gallas S, Emery E, Loiseau H, Lejeune JP, Lonjon M, Proust F, Boetto S, Coulbois S, Auque J, Boulliat J (2008) Outcome in 53 patients with spinal cord cavernomas. Surg Neurol 70:176-181 discussion 181

16. McCormick PC, Michelsen WJ, Post KD, Carmel PW, Stein BM (1988) Cavernous malformations of the spinal cord. Neurosurgery 23:459-463

17. Mindea SA, Yang BP, Shenkar R, Bendok B, Batjer HH, Awad IA (2006) Cerebral cavernous malformations: clinical insights from genetic studies. Neurosurg Focus 21:e1

18. Nagib MG, O'Fallon MT (2002) Intramedullary cavernous angiomas of the spinal cord in the pediatric age group: a pediatric series. Pediatr Neurosurg 36:57-63

19. Noudel R, Litre F, Vinchon M, Patey M, Rousseaux P (2008) Intramedullary spinal cord cavernous angioma in children: case report and literature review. Childs Nerv Syst 24:259263

20. Odom GL, Woodhall B, Margolis G (1957) Spontaneous hematomyelia and angiomas of the spinal cord. J Neurosurg 14:192-202 
21. Robinson JR, Awad IA, Little JR (1991) Natural history of the cavernous angioma. J Neurosurg 75:709-714

22. Sandalcioglu IE, Wiedemayer H, Gasser T, Asgari S, Engelhorn T, Stolke D (2003) Intramedullary spinal cord cavernous malformations: clinical features and risk of hemorrhage. Neurosurg Rev 26:253-256

23. Santoro A, Piccirilli M, Brunetto GM, Delfini R, Cantore G (2007) Intramedullary cavernous angioma of the spinal cord in a pediatric patient, with multiple cavernomas, familial occurrence and partial spontaneous regression: case report and review of the literature. Childs Nerv Syst 23:1319-1326

24. Scott RM, Barnes P, Kupsky W, Adelman LS (1992) Cavernous angiomas of the central nervous system in children. J Neurosurg 76:38-46

25. Tu YK, Liu HM, Chen SJ, Lin SM (1999) Intramedullary cavernous haemangiomas: clinical features, imaging diagnosis, surgical resection and outcome. J Clin Neurosci 6:212-216
26. Vishteh AG, Sankhla S, Anson JA, Zabramski JM, Spetzler RF (1997) Surgical resection of intramedullary spinal cord cavernous malformations: delayed complications, long-term outcomes, and association with cryptic venous malformations. Neurosurgery 41:1094-1100 discussion 1100-1091

27. Vishteh AG, Zabramski JM, Spetzler RF (1999) Patients with spinal cord cavernous malformations are at an increased risk for multiple neuraxis cavernous malformations. Neurosurgery 45:3032 discussion 33

28. Yasui T, Komiyama M, Iwai Y, Yamanaka K, Matsusaka Y, Morikawa T, Ishiguro T (2005) A brainstem cavernoma demonstrating a dramatic, spontaneous decrease in size during follow-up: case report and review of the literature. Surg Neurol 63:170-173 discussion 173

29. Zevgaridis D, Medele RJ, Hamburger C, Steiger HJ, Reulen HJ (1999) Cavernous haemangiomas of the spinal cord. A review of 117 cases. Acta Neurochir (Wien) 141:237-245 